\title{
An Experimental Study of Bond Behavior of Micro Steel Fibers Added Self-compacting Concrete with Steel Reinforcement
}

\author{
Abdul Salam¹, Shah Room², Shahid Iqbal ${ }^{3 *}$, Khalid Mahmood³, Qaiser Iqbal ${ }^{3}$ \\ 1 Department of Civil Engineering, CECOS University of IT and Emerging Sciences, F-5, Phase-6, Hayatabad, Peshawar, Pakistan \\ 2 Department of Civil Engineering Technology, University of Technology Nowshera, Amangarh, 24100 Nowshera, Pakistan \\ ${ }^{3}$ Department of Civil Engineering, Sarhad University of Science and Information Technology, Peshawar, Pakistan \\ * Corresponding author, e-mail: shahid.civil@suit.edu.pk
}

Received: 28 February 2019, Accepted: 14 July 2020, Published online: 25 August 2020

\begin{abstract}
The obstruction offered by the surrounding concrete to the pulling out of embedded steel bar is known as bond strength. Steel fibers addition to concrete improves its bond strength by arresting the cracks due to their bridging effect. Bond failure occurs when cracks in the surrounding concrete initiates, providing enough space for bar to be pulled-out. Micro steel fibers efficiently control the formation of micro cracks and may improve bond strength to a greater extent compared to the longer steel fibers. However, it reduces the workability of concrete which is of greater importance in case of self-compacting concrete (SCC). Reduction of workability is less pronounced when straight micro steel fibers are used due to their shorter lengths and straight geometry. Thus, different amount of straight micro steel fibers $(0.25 \%, 0.5 \%, 0.75 \%)$ were incorporated in to SCC to investigate their fresh and mechanical properties with major emphasis on the bond strength. Results indicate that steel fibers addition to SCC improve the splitting tensile strength and bond strength significantly with a maximum increase of $33.5 \%$ and $54.9 \%$ respectively with $0.75 \%$ fibers addition. An equation is proposed for the calculation of bond strength with micro steel fibers addition to SCC with a maximum variation of $4 \%$ to those of experimental values.
\end{abstract}

Keywords

bond strength, micro steel fibers, self-compacting concrete, micro cracks, mechanical properties

\section{Introduction}

Self-compacting concrete (SCC) is highly flow-able, nonsegregating concrete which has the property to flow under its own weight filling the formwork without the use of compaction equipment [1]. It is produced by adding some minerals and admixtures to the normal vibrated concrete (NVC). Use of smaller size aggregates and different fillers ensures better flow and micro structural properties of SCC [2, 3].

As concrete is brittle in nature, fibers are added to it to make it ductile. Different types of natural and artificial fibers have been added to concrete in recent past. One of the most commonly used fibers are steel fibers. Steel fibers are classified into micro and macro fibers on the basis of their size and geometry. Micro steel fibers possesses high tensile strength and straight geometry with length ranging from $10 \mathrm{~mm}$ to $25 \mathrm{~mm}$ while macro fibers have lengths ranging from $25 \mathrm{~mm}$ to $75 \mathrm{~mm}$ and are produced in different geometries including hooked end, cone end, twisted fibers etc. for mechanical anchorage. Fibers addition to concrete greatly improves its mechanical properties. This is the reason for fiber reinforced concrete utilization in the last decades for various partial and full structural applications, including slabs on grade [4], overlays [5], precast roof elements [6], refractory linings in industrial equipment [7].

The orientation and distribution of steel fibers in concrete have major effect on the properties of concrete. The use of vibrators for compaction of fiber reinforced concrete has adverse effects on the distribution and alignment of fibers in it. However, the rheological properties of SCC provide uniform dispersion of steel fibers, which is difficult to achieve in NVC [6]. Previous studies have reported that the flow and mechanical properties of SCC are dependent on the amount, geometry and distribution of steel fibers in concrete $[8,9]$. Concrete is brittle in nature, whereas amalgamation of steel fibers provides stability, improves its impact resistance, bond strength and makes it ductile [10-12]. 
Bond behavior of reinforcements in concrete has crucial role in transfer of loads from concrete to reinforcements. Bond strength has three components i.e. adhesion, friction and mechanical anchorage, however, mechanical interaction is the most important component in case of deformed bars [13]. Adequate bond ensures homogeneity of reinforced concrete whereas, poor bond results in ineffective beam action making design equations invalid [14]. It has been reported that SCC has 27-65\% higher bond strength with reinforcements because of its improved micro structure compared to that of NVC [15]. Thus, this effect will also be prominent when fibers are added to concrete resulting in better bonding between the fibers and surrounding concrete matrix exhibiting better performance compared to normal vibrated concrete. Steel fibers addition increase splitting resistance and ductility of concrete resulting in the enhanced bond strength [16]. A previous study reported that bond strength of $16 \mathrm{~mm}$ dia bar in concrete increases by $32 \%$ when $0.5 \%$ hooked end steel fibers were added to it, however, the compressive strength and bond strength decreases with the use of $0.75 \%$ steel fibers [12], because the longer hooked end steel fibers create hindrance to the compaction of NVC when used in higher contents, resulting in the reduction of concrete strengths. However, shorter fibers cause less reduction in the workability and are expected to improve concrete strength at higher fiber contents as well, or when better workability is desired specially in case of SCC.

\section{Research aim and novelty}

Various kinds of steel fibers are added to concrete. The reduction in the workability of concrete is more pronounced when macro steel fibers are added to it because of their greater length and deformed shape compared to micro steel fiber addition owing to their shorter lengths and smooth geometry [17]. Workability is of major concern in SCC, therefore, the use of micro steel fibers in SCC is advantageous. Pull-out load applied on a reinforcement bar embedded in concrete is resisted by the chemical adhesion, friction and mechanical anchorage provided by the ribs of steel bars. When pull-out load increases further, at a certain ultimate value, cracks are initiated in the concrete surrounding reinforcement bars, initiating the bond failure resulting in pulling-out of bar from the concrete. Inclusion of steel fibers into concrete improves the bond strength of reinforcement in concrete by arresting cracks, thus providing greater mechanical anchorage. Formation of micro cracks provide enough space for bars to be pulled-out. It has been reported that, by arresting the formation of micro cracks, micro steel fibers are more effective in tensile strength improvement of concrete but are pulled-out once cracks are formed due to their shorter length, while macro fibers resists the propagation of cracks once initiated and are therefore more favorable in improving the toughness of concrete [18]. Therefore, it is expected that the addition of micro steel fibers may provide greater improvement in the bond strength by arresting micro cracks in concrete providing better confinement. However, there is limited literature available depicting the effect of micro steel fiber content on the bond strength of concrete. Thus, the main aim of this study is to investigate the effect of straight micro steel fibers addition on the bond strength of reinforcements in SCC. The objectives of this study are:

1. To examine the influence of added micro steel fibers quantity on the fresh state properties of SCC i.e. density, workability and air content.

2. To study the effect on the compressive and splitting tensile strength when micro steel fibers are incorporated into $\mathrm{SCC}$.

3. To evaluate the effect on the bond between rebars and surrounding SCC with micro steel fibers incorporation.

Pull-out tests have been used for calculation of bond strength using Eq. (1).

$$
\mu=\frac{p}{\pi l_{d} d_{b}}
$$

where $\mu$ bond strength, $p=$ Pull-out force, $l_{d}=$ development length, $d_{b}=$ bar diameter.

\section{Materials}

\subsection{Cement and filler}

CEM I 32.5N manufactured by "CHEERAT CEMENT" was used for all the mixes. Waste glass powder (GP) was used as filler in the production of SCC. The GP used was produced in PCSIR labs in Peshawar, Pakistan and the average particle size of was kept less than $75 \mu \mathrm{m}$.

\subsection{Aggregates}

Aggregates were obtained from local supplier and lab tests were conducted to find the relevant properties. Fine aggregates (FA) 0-4 mm and coarse aggregate (CA) 4-12.5 $\mathrm{mm}$ in size having water absorption of $1.54 \%$ and $1.01 \%$, specific gravity of 2.65 and 2.75 respectively were used in this study. Fineness modulus of fine aggregate as tested in laboratory was 2.78 . 


\subsection{Super plasticizer (SP)}

High range water reducer used for production of SCC in this study was manufactured by SIKA with commercial name "Ultra-Super Plast-470" and specific gravity of 1.155.

\subsection{Steel fibers}

Straight micro steel fibers (SF) as shown in Fig. 1, having length of $13 \mathrm{~mm}, 0.2 \mathrm{~mm}$ in dia, aspect ratio of 65 and $2500 \mathrm{MPa}$ strength were added to concrete in different proportions.

\section{Experimental program}

Trial mixes were performed to finalize the concrete mix for SCC. After the finalization of concrete mix, different contents of steel fibers were added to concrete i.e. $0.25 \% v / f$, $0.5 \% v / f$, and $0.75 \% v / f$. Coarse and fine aggregates were dry mixed in pan mixer for $30 \mathrm{sec}$ and water as per the water absorption capacity of aggregates was added and further mixed for $30 \mathrm{sec}$. GP and cement were added to mixed aggregates and mixed for $1 \mathrm{~min}$. Water and superplastizer mixed together were added gradually to the mixed ingredients and mixed for $2 \mathrm{~min}$. Steel fibers were added slowly towards the end to avoid overmixing and balling effect and mixed further for $30 \mathrm{sec}$. The slump flow was visually inspected for signs of bleeding or segregation, which were not present. Fresh concrete samples from center and sides of the slump flow were collected, weighted and washed to check quantity of coarse aggregates and fibers for indication of segregation but uniform proportions were noted. Fresh state and mechanical properties of concrete were studied. ASTM testing standard C1611/C1611M was adopted to test the workability of SCC while, ASTM C138/ $\mathrm{C} 138 \mathrm{M}$ was used to determine the density and air content of fresh concrete. Mechanical properties investigated

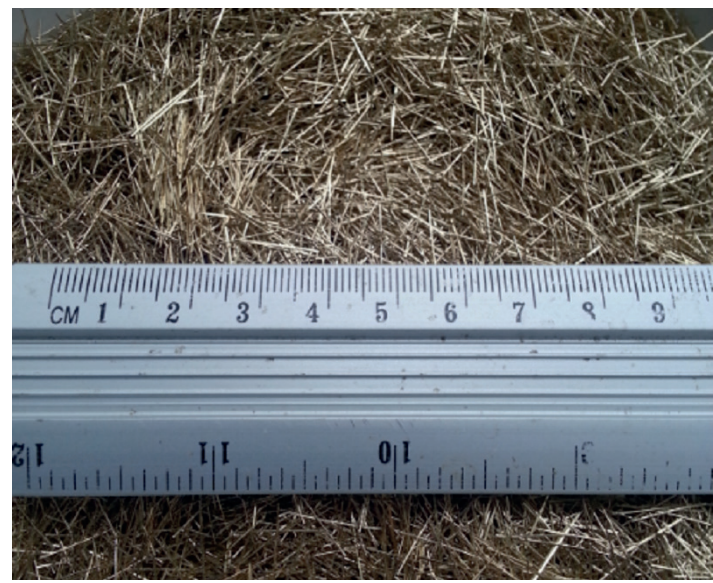

Fig. 1 Straight micro steel fibers include compressive (CS), splitting tensile (STS) and bond strength (BS). Six cylinders $100 \mathrm{~mm}$ in diameter and $200 \mathrm{~mm}$ in height were casted for each concrete mix for testing the compressive and splitting tensile strength of concretes. Moist curing up to the date of testing was performed as per ASTM C192/C192M after de-molding of the concrete samples. At the age of 28 days, for all concrete mixes, three cylinders were tested as per ASTM C39/ C39M applying load at the rate of $0.25 \mathrm{MPa} / \mathrm{sec}$ while three were tested for concrete splitting tensile strength as per ASTM C496/C496M applying load at a constant rate of $1 \mathrm{MPa} / \mathrm{min}$. Three cube samples were casted for each concrete mix with size of $150 \mathrm{~mm}$, embedded with $16 \mathrm{~mm}$ diameter bars to test the bond strength by applying pull-out load at a constant rate of $0.1 \mathrm{KN} / \mathrm{sec}$. The arrangement for pulling-out test is shown in Fig. 2.

\section{Results and discussions}

\subsection{Concrete mix composition}

SCC mix proportion for the control mix was finalized using trial mixes with the support from available literature. The minimum slump flow requirement of SCC in this study was set at $650 \mathrm{~mm}$ and per EFNARC guidelines for SCC [19] and concrete compressive strength of $24 \mathrm{MPa}$ at water cement ration of 0.5 . After finalization of concrete mix design for control mix, steel fibers in different percentages were added to concrete. Mix proportions of concrete mixes in this study are summarized in Table 1.

\subsection{Fresh concrete properties}

Slump flow test was used to find the workability of all concrete mixes as shown in Fig. 2. Table 2 represents results for fresh state properties of all the mixes. Results indicate that increase in the amount of steel fiber added, causes

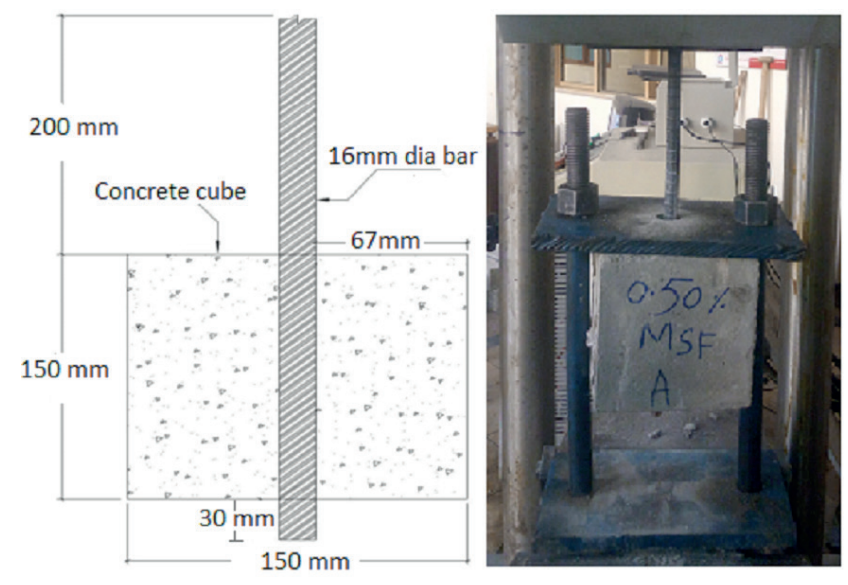

Fig. 2 Pull-out test arrangement 
Table 1 Concrete mix composition

\begin{tabular}{lccccccc}
\hline \multirow{2}{*}{ Concrete mix } & \multicolumn{7}{c}{ Content $\left(\mathrm{kg} / \mathrm{m}^{3}\right)$} \\
& Cement & GP & CA & FA & SF & SP & Water \\
\hline Mix-0 & 400 & 140 & 630 & 1024 & 0 & 14 & 225 \\
Mix-0.25 & 400 & 140 & 630 & 1024 & 20 & 14 & 225 \\
Mix-0.5 & 400 & 140 & 630 & 1024 & 40 & 14 & 225 \\
Mix-0.75 & 400 & 140 & 630 & 1024 & 60 & 14 & 225 \\
\hline & & & & & & \\
& Table 2 Fresh concrete properties & & \\
\hline Concrete & Slump flow & T500 & Density & Air content \\
mix & (mm) & & $(\mathrm{sec})$ & $\left(\mathrm{kg} / \mathrm{m}^{3}\right)$ & $(\%)$ \\
\hline Mix-0 & 760 & & 4 & 2406 & 2.62 \\
Mix-0.25 & 720 & & 6 & 2410 & 2.87 \\
Mix-0.5 & 700 & & 7 & 2413 & 3.56 \\
Mix-0.75 & 690 & & 8 & 2416 & 4.06 \\
\hline
\end{tabular}

a gradual decrease in the workability of concrete. Slump flow values of concrete mixes with fiber contents of $0.25 \%$, $0.5 \%$ and $0.75 \%$ decreased by $5.26 \%, 7.89 \%, 9.21 \%$ respectively compared to the control mix. At $0.75 \%$ fiber content, T500 time becomes double, likewise slump flow values, it indicates the decrease in workability by creating hindrance in concrete flow-ability (Fig. 3). However, at $0.75 \%$ fiber content, the slump flow value is still above the threshold value of $650 \mathrm{~mm}$.

Moreover, air content increases with the increase of steel fibers but the density remains nearly constant. Fig. 4 represents the variation in the workability and air content of all concrete mixes.

Numerous researchers reported decrease in workability of concrete due to the addition of steel fibers to it [20-25]. Steel fiber reinforced SCC with slump flow in the range of 560-700 mm, without segregation, have been produced in a previous research work [26]. A decrease of $10.5 \%$ in the slump flow by addition of $0.75 \%$ steel fibers to SCC have been reported by a previous research [27], which is in agreement with the current study.

\subsection{Hardened concrete properties}

Hardened concrete properties included compressive strength, splitting tensile strength and bond strength, all tested at the concrete age of 28 days after moist curing. The test results for all the concrete types are summarized in Table 3 along with their standard deviations (SD).

\subsubsection{Compressive strength}

Compressive strength test results at the age of 28 days are summarized in Table 3. Incorporation of fibers into SCC has shown minimal variation on the compressive strength

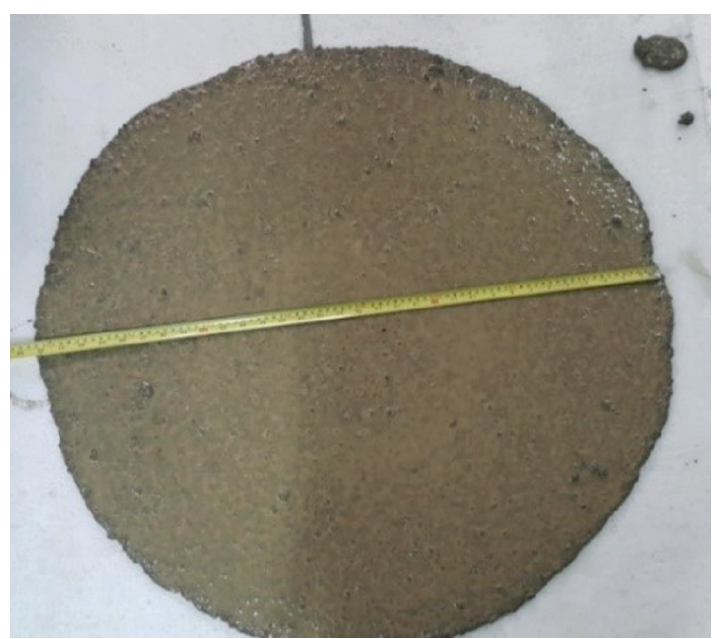

Fig. 3 Slump flow test

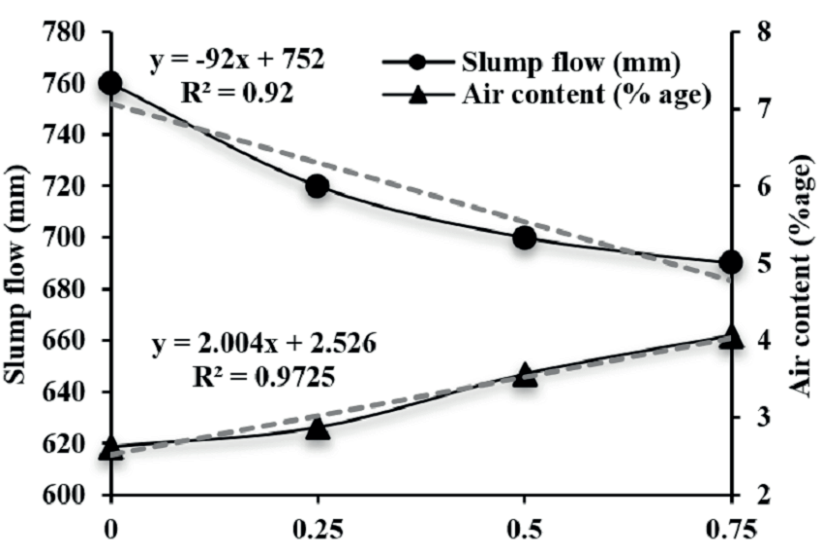

Micro straight steel fiber content (\% VF)

Fig. 4 Variation of slump flow and air content

Table 3 Hardened concrete properties

\begin{tabular}{lcccccc}
\hline \multirow{2}{*}{$\begin{array}{l}\text { Concrete } \\
\text { Mix }\end{array}$} & \multicolumn{2}{c}{ CS } & \multicolumn{2}{c}{ STS } & \multicolumn{2}{c}{ BS } \\
& MPa & SD & MPa & SD & MPa & SD \\
\hline Mix-0 & 25.8 & 0.18 & 2.68 & 0.06 & 10.24 & 0.15 \\
Mix-0.25 & 25.9 & 0.29 & 2.9 & 0.07 & 11.64 & 0.46 \\
Mix-0.5 & 26.7 & 0.26 & 3.19 & 0.07 & 13.94 & 0.39 \\
Mix-0.75 & 27 & 0.23 & 3.58 & 0.09 & 15.86 & 0.21 \\
\hline
\end{tabular}

of concrete with a maximum increase of $4.77 \%$ with $0.75 \%$ fibers addition compared to that of the reference concrete without fibers as graphically presented in Fig. 5.

Although, there is slight variation in compressive strength of concrete but the major change is in the failure mode as the concrete with steel fibers exhibits reduced brittleness compared to the concrete without fibers.

The concrete cylindrical samples without fibers disintegrated after crushing under the compressive load but the samples with steel fibers remained intact due to the bridging effect of steel fibers in concrete as shown in Fig. 6. 


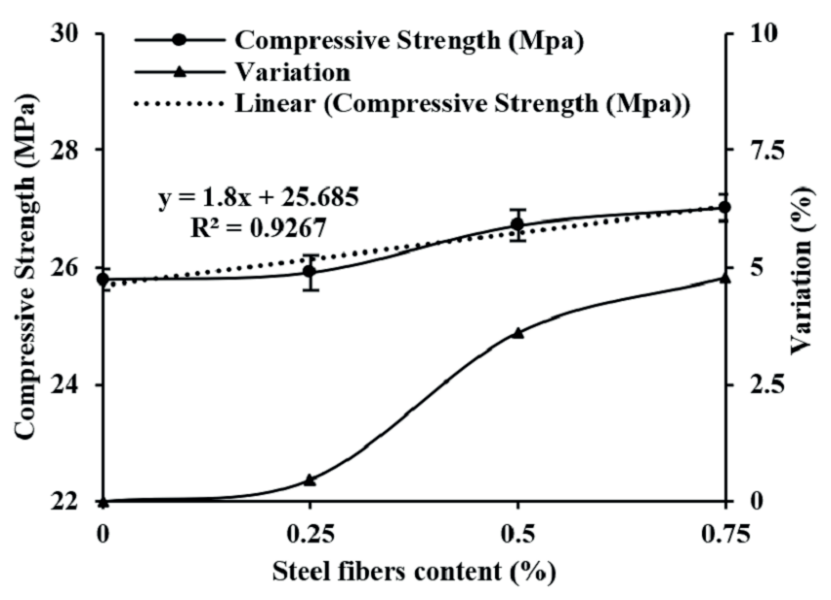

Fig. 5 Compressive strength and percentage variation

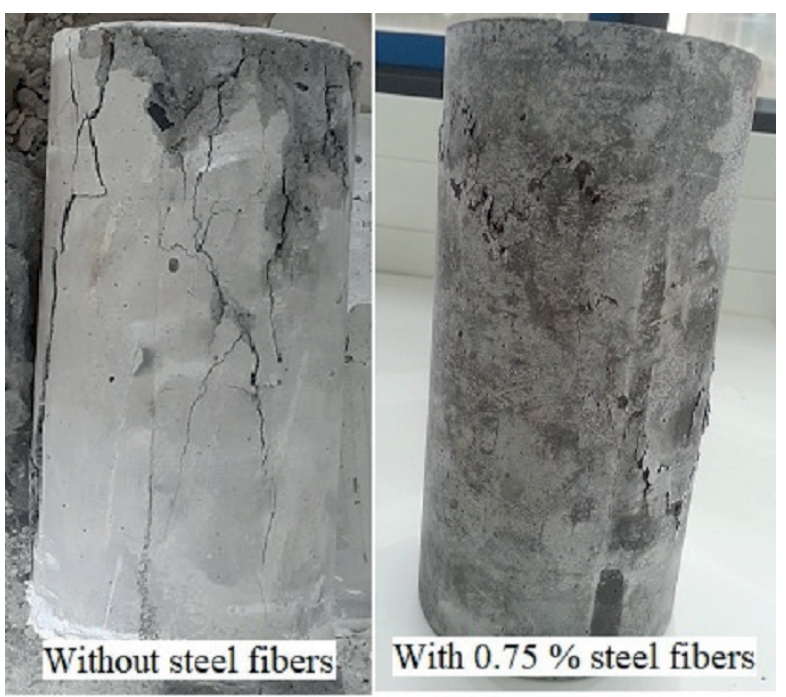

Fig. 6 Failed compression test samples

Identical results have been reported by the other researchers. A previous study reported that inclusion of steel fibers to concrete do not significantly influence the compressive strength; however, the concrete failure becomes ductile [28]. Another study reported $6.98 \%$ rise in compressive strength of concrete when $0.5 \% \mathrm{v} / \mathrm{f}$ of hooked end steel fibers are added to it [29]. Thus, steel fibers addition has no major effect on its compressive strength.

\subsubsection{Splitting tensile strength}

Test results for splitting tensile strength of all the concrete types at the age of 28 days are summarized in Table 3. Despite the use of lower contents of steel fibers, there is significant increase in the tensile strength of concrete on the addition of micro steel fibers to it. Fig. 7 shows the results of splitting tensile strength containing different amount of steel fibers and the percentage strength variation with respect to the control mix.

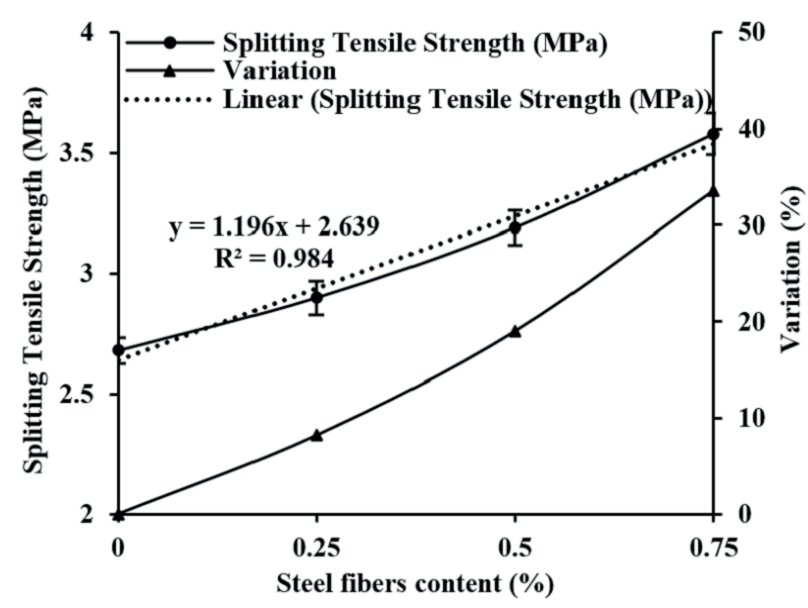

Fig. 7 Splitting tensile strength and variation

The increase in splitting tensile strength of concrete is $8.2 \%, 19 \%$ and $33.5 \%$ respectively with addition of $0.25 \%, 0.5 \%$ and $0.75 \% v / f$ of steel fibers respectively to the reference concrete. The reason may be the bridging effect of shorter steel fibers which are more efficient in delaying the formation of cracks, increasing the tensile strength by good amount.

Similar effects of steel fibers addition on the splitting tensile strength of concrete have been reported in earlier studies. Splitting tensile strength increases of $18 \%$ have been reported by the addition of up to $0.75 \%$ micro steel fibers to high strength lightweight SCC [17]. There is improvement of $28 \%$ in the tensile strength of concrete when $1 \% v / f$ of hooked-end steel fibers, $60 \mathrm{~mm}$ long, are added to high strength concrete [30]. Thus, steel fibers addition has significant impact on the splitting tensile strength of concrete, however the increase is higher in case of micro steel fibers addition compared to that of macro steel fibers.

\subsubsection{Bond strength}

The test results for the bond strength calculated using pullout tests are listed in Table 4. Results indicate significant increase in bond strength of reinforcement with concrete by incorporating micro steel fibers into concrete.

Table 4 Bond strength results

\begin{tabular}{lcccc}
\hline $\begin{array}{l}\text { Concrete } \\
\text { mix }\end{array}$ & $\begin{array}{c}\text { Fiber } \\
\text { content } \\
(\%)\end{array}$ & $\begin{array}{c}\text { Average } \\
\text { Pull-out load } \\
(\mathrm{KN})\end{array}$ & $\begin{array}{c}\text { Average } \\
\text { bond strength } \\
(\mathrm{MPa})\end{array}$ & $\begin{array}{c}\text { Increase } \\
(\%)\end{array}$ \\
\hline Mix-0 & 0 & 77.24 & 10.24 & 0 \\
Mix-0.25 & 0.25 & 85.22 & 11.64 & 13.7 \\
Mix-0.5 & 0.5 & 105.08 & 13.94 & 36.1 \\
Mix-0.75 & 0.75 & 119.56 & 15.86 & 54.9 \\
\hline
\end{tabular}


When $0.25 \%, 0.5 \%$ and $0.75 \%$ steel fibers are added to SCC, there is increase in bond strength of reinforcement and surrounding concrete by $13.7 \%, 36.1 \%$ and $54.9 \%$ respectively. A previous study reported a maximum of $22 \%$ increase in bond strength by addition of $0.75 \% v / f$ hooked end macro steel fibers to concrete. Steel bars are pulled-out with the formation of micro crack in the surrounding concrete. Thus, it may be inferred from the results that micro steel fibers are extra efficient in improving the bond behavior by delaying the initiation of micro cracks compared to the longer deformed fibers which are effective in delaying the propagation of cracks once they are formed. The test results are graphically presented in Fig. 8.

It was observed from the tested samples that, in the reference concrete with no added fibers, at ultimate pull-out load, splitting occurred in the concrete surrounding the reinforced bar causing the bond failure. However, when steel fibers were added to concrete in different content, the formation of cracks were avoided by the bridging effect of fibers causing the pull-out failure at a significantly higher loads compared to that of the reference concrete as shown in Fig. 9.

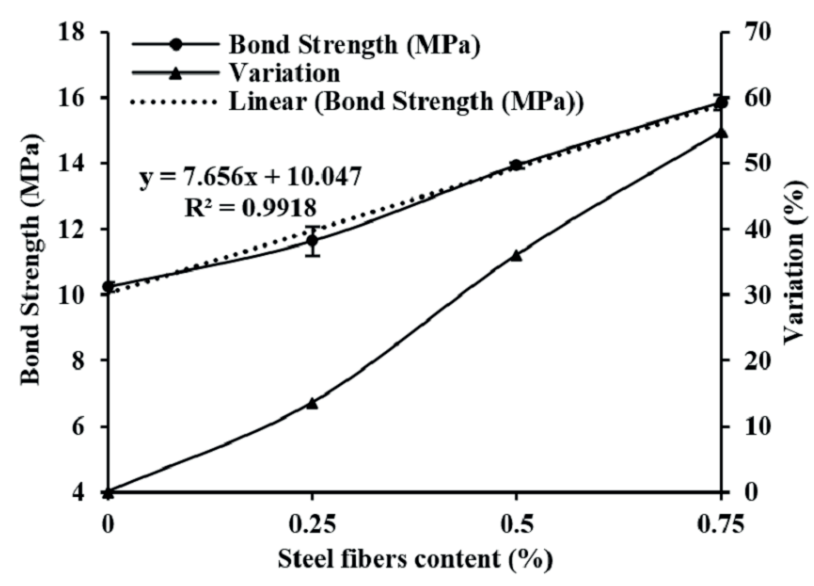

Fig. 8 Bond strength variation

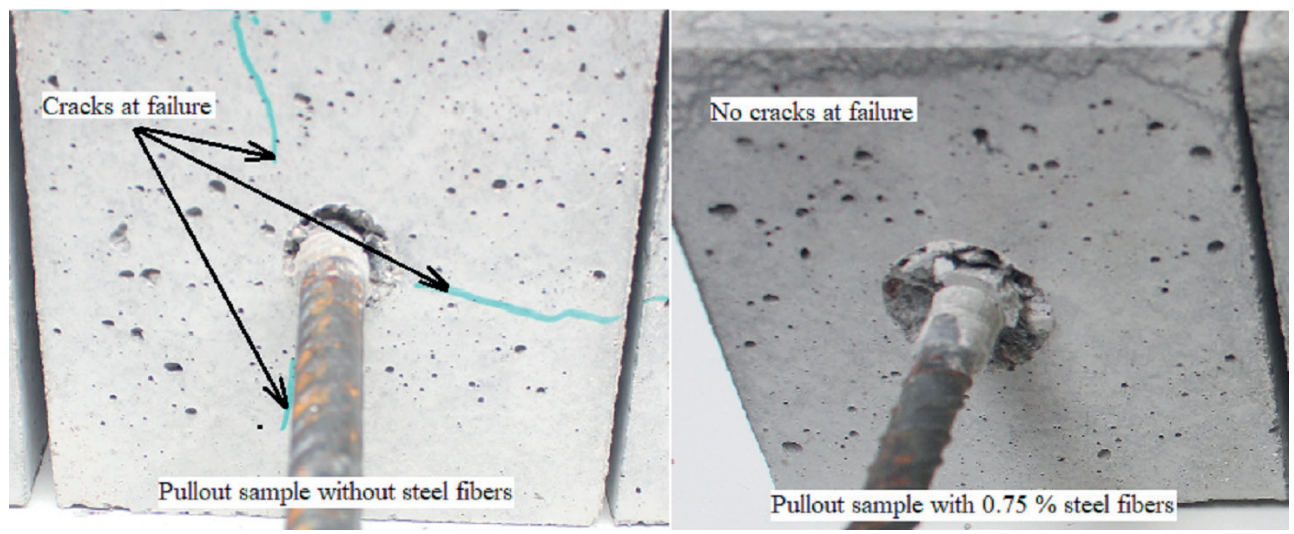

Fig. 9 Pull-out samples after testing
A previous study reported splitting failure of all the pull-out samples when normal vibrated concrete (NVC) was used with no fibers addition to it [31]. Similarly, by adding hooked end steel fibers to NVC, splitting failure was reported for all the tested samples [12]. GarciaTaengua et al. [32] in 2016 used steel fibers having lengths in the range of 35-60 $\mathrm{mm}$ and reported that shorter steel fibers have greater influence on the bond strength compared to the longer fibers. Thus, short micro steel fibers effectively delays the formation of cracks by bridging effect, providing better confinement to the reinforcement bars and improving the bond strength.

\subsubsection{Estimation of bond strength}

On the basis of previous researches, equations for calculation of bond strength of reinforcements in concrete have been proposed by Orangun et al. [33] and MC2010 [34] with splitting failure and with splitting failure given by Eq. (2) and Eq. (3) and Eq. (4) respectively. These equations are quite useful in calculating the bond strength of reinforcements in concretes with different compressive strengths, but do not consider the influence of added fibers on the bond strength. While Harajli [35], Yazici and Arel [36] and Li et al. [37] have proposed equations for calculation of bond strength of reinforcing steel bars with fiber reinforced concrete given as Eq. (5), Eq. (6), and Eq. (7) respectively.

$$
\begin{aligned}
& \frac{u_{c}}{\sqrt{f_{c}^{\prime}}}=0.1+0.25 \frac{c_{\min }}{d}+4.15 \frac{d}{l_{d}} \\
& u_{c}=2.5 \sqrt{f_{c m}} \\
& u_{c}=7\left(\frac{f_{c m}}{25}\right)^{0.25}
\end{aligned}
$$


$u_{c}=0.95 c_{f} \sqrt{f_{c}^{\prime}}\left(\frac{c}{d}\right)^{\frac{2}{3}}$

$u_{c}=\frac{\left(9.38+0.009\left(\frac{l_{f}}{d_{f}}\right)+0.147 f_{c}^{\prime}+3.07 f_{t}+0.193 c-0.004 K-0.123 E_{c}\right)}{l_{d} d}$

$u_{c}=\left(0.76+2.24 \frac{d}{l_{d}}\right)\left(3.27+k_{1} \frac{c}{d}+k_{2} \rho_{s v}\right) f_{t}$

Where $u_{c}$ is the ultimate bond strength, $f_{c}^{\prime}$ is 28 days concrete compressive strength, $c_{\min }$ is minimum concrete cover, $d$ is diameter of the embedded bar, $l_{d}$ is embedded length of the bar, $f_{c m}$ is mean compressive strength of concrete, $c_{f}$ is factor for steel fibers taken as 1 when $\frac{V_{f} l_{f}}{d_{f}} \leq 0.25$ and $c_{f}=1+0.34 \sqrt{\frac{V_{f} l_{f}}{d_{f}}}$ for $\frac{V_{f} l_{f}}{d_{f}}>0.25$ is concrete cover $l_{f}$ is length of steel fibers, $d_{f}$ is diameber of steel fibers, $f_{t}$ is tensile strength of concrete, $K$ is fibers content in $\mathrm{kg} / \mathrm{m}^{3}, E_{c}$ is modulus of elasticity of concrete, $\rho_{s v}$ is transverse reinforcement ratio, $k_{1}$ and $k_{2}$ are constants with values of 0.32 and 17.74 in case of steel fiber reinforced highstrength concrete.

Calculations are performed using all these equations and the results for predicted bond strength are summarized in Table 5.

Fig. 10 graphically presents the experimental bond strength results in the current study and those calculated using equations proposed in previous studies. Orangun et al. [33] and MC2010 [34] equations do not consider the effect of steel fibers addition into concrete on the ultimate bond strength and thus results in conservative values. Equations proposed by Harajli [35], Yazici and Arel [36] and Li et al. [37] take into account the effect of steel fibers addition into concrete, however, Yazici and Arel [36] equation

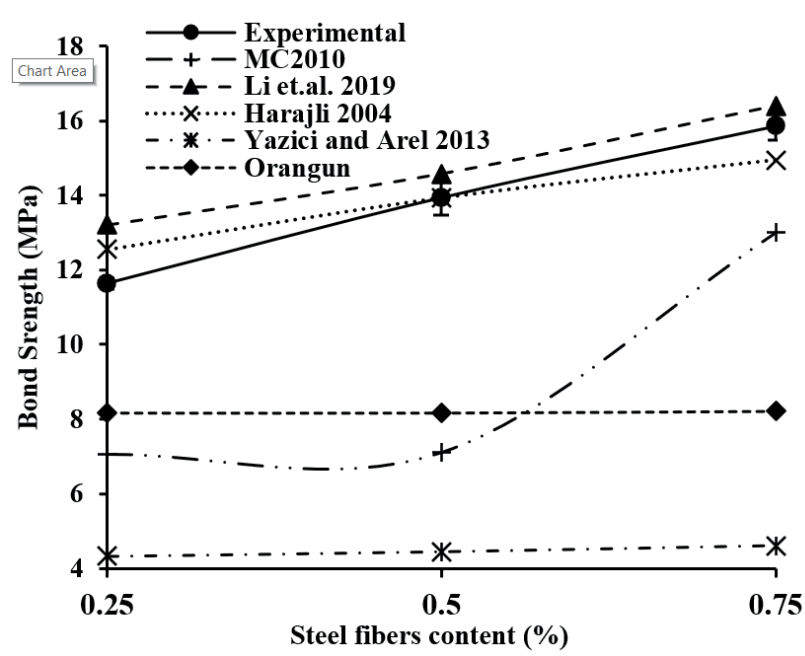

Fig. 10 Comparison of bond strength values

predicts significantly lower ultimate bond strength. The reason is that there is no consideration of variation in embedded length of reinforcements into concrete resulting in lower bond strength prediction with increase in embedded length. The prediction by Harajli [35] equation are close to the experimental values, however the values are slightly over estimated with lower steel fiber content $(0.25 \% v / f)$ and slightly under estimated with higher steel fiber content $(0.75 \% v / f)$. The equation proposed by Li et al. [37] gives best predicted bond strength values with similar trend in the increase to those of experimental values, when steel fibers content increases. However, the values are slightly over estimated. The reason may be that they have developed their equation considering high strength fiber reinforced concrete while normal strength fiber reinforced concrete is used in the current study. Nevertheless, Harajli [35] and Li et al. [37] equations can be used to calculated ultimate bond strength of reinforcements in fiber reinforced concrete with fair accuracy.

Table 5 Bond strength calculations

\begin{tabular}{|c|c|c|c|c|c|c|c|c|c|}
\hline \multirow{2}{*}{$\begin{array}{l}\text { Concrete } \\
\operatorname{mix}\end{array}$} & \multirow{2}{*}{$\begin{array}{c}\text { Sample } \\
\text { No. }\end{array}$} & \multirow{2}{*}{$\begin{array}{c}\text { Average } \\
\text { compressive } \\
\text { strength }\end{array}$} & \multicolumn{2}{|c|}{ Experimental } & \multirow{2}{*}{$\begin{array}{l}\text { Orangun } \\
\text { Eq. bond } \\
\text { strength } \\
\text { Mpa }\end{array}$} & \multirow{2}{*}{$\begin{array}{l}\text { MC2010 } \\
\text { Bond } \\
\text { strength } \\
(\mathrm{MPa})\end{array}$} & \multirow{2}{*}{$\begin{array}{l}\text { Harajli } \\
\text { eq. bond } \\
\text { strength } \\
(\mathrm{MPa})\end{array}$} & \multirow{2}{*}{$\begin{array}{l}\text { Yazici \& } \\
\text { Arel eq. bond } \\
\text { strength } \\
(\mathrm{MPa})\end{array}$} & \multirow{2}{*}{$\begin{array}{c}\text { Li et.al. } \\
\text { eq Bond } \\
\text { strength } \\
(\mathrm{MPa})\end{array}$} \\
\hline & & & $\begin{array}{l}\text { Pull-out load } \\
\text { (KN) }\end{array}$ & $\begin{array}{l}\text { Bond strength } \\
\text { (MPa) }\end{array}$ & & & & & \\
\hline \multirow{3}{*}{ Mix-0.25 } & 1 & 26.03 & 85.2 & 11.3 & 8.16 & 7.07 & 12.59 & 4.32 & 13.21 \\
\hline & 2 & 25.83 & 86.33 & 11.45 & 8.07 & 7.06 & 12.54 & 4.32 & 13.21 \\
\hline & 3 & 25.86 & 84.13 & 12.16 & 8.08 & 7.06 & 12.55 & 4.32 & 13.21 \\
\hline \multirow{3}{*}{ Mix- 0.5} & 4 & 26.74 & 105.71 & 14.02 & 8.22 & 7.12 & 13.95 & 4.44 & 14.58 \\
\hline & 5 & 26.8 & 104.44 & 13.85 & 8.23 & 7.12 & 13.97 & 4.44 & 14.58 \\
\hline & 6 & 26.63 & 105.1 & 13.94 & 8.2 & 7.11 & 13.92 & 4.44 & 14.58 \\
\hline \multirow{3}{*}{ Mix-0.75 } & 7 & 26.96 & 118.11 & 15.66 & 8.25 & 12.98 & 14.94 & 4.59 & 16.40 \\
\hline & 8 & 27.1 & 121.37 & 16.1 & 8.27 & 13.01 & 14.98 & 4.60 & 16.40 \\
\hline & 9 & 27.02 & 119.2 & 15.81 & 8.26 & 13.00 & 14.96 & 4.60 & 16.40 \\
\hline
\end{tabular}




\section{Conclusions}

This study highlights the effects of straight micro steel fibers addition on the fresh and mechanical properties of SCC with a special emphasis on the bond strength of reinforcements in concrete. Following conclusions may be drawn from this research work:

4. Workability decreases with the addition of straight micro steel fibers to SCC but the effect is not significant because of its shorter length and straight geometry. Thus, it is beneficial to use these fibers when self-compaction is desired.

5. The compressive strength of concrete is not significantly influenced by the inclusion of steel fibers into SCC.

6. There is noteworthy improvement in the splitting tensile strength when micro steel fibers are added to $\mathrm{SCC}$. The reason may be the effective resistance to the formation of cracks by shorter fibers. The maximum increase was up to $33.5 \%$ with the addition of $0.75 \%$ fibers to SCC.

7. The bond strength of reinforcements in SCC is greatly affected by the addition of micro steel fibers to it. The formation of cracks is resisted by the bridging effect of steel fibers improving the bond strength significantly. With the addition of $0.75 \%$ micro steel fibers to SCC, bond strength improved by $54.9 \%$.

\section{References}

[1] ACI "237R-07: Self-Consolidating Concrete", American Concrete Institute, Farmington Hills, MI, USA, 2007.

[2] De Weerdt, K., Kjellsen, K. O., Sellevold, E., Justnes, H. "Synergy between fly ash and limestone powder in ternary cements", Cement and Concrete Composites, 33(1), pp. 30-38, 2011.

https://doi.org/10.1016/j.cemconcomp.2010.09.006

[3] Rizwan, S. A., Bier, T. A. "Blends of limestone powder and fly-ash enhance the response of self-compacting mortars", Construction and Building Materials, 27(1), pp. 398-403, 2012.

https://doi.org/10.1016/j.conbuildmat.2011.07.030

[4] Groth, P., Nemegeer, D. "The use of steel fibres in self-compacting concrete", In: Proceedings of the First International RILEM Symposium on Self-Compacting Concrete, Stockholm, Sweden, 1999, pp. 497-507.

[5] Carlswärd, J., Emborg, M. "Shrinkage cracking of steel fibre reinforced self compacting concrete overlays test methods and theoretical modelling", In: Proceedings of the 5th International RILEM Symposium on Self-Compacting Concrete, Gent, Belgium, 2007, pp. 793-798.

[6] Ferrara, L., Meda, A. "Relationships between fibre distribution, work ability and the mechanical properties of SFRC applied to precast roof elements", Materials and Structures, 39, pp. 411-420, 2006. https://doi.org/10.1617/s11527-005-9017-4
8. Equations proposed by Harajli [35] and Li et al. [37] gives fair results for the bond strength and can thus be effectively used to predict the ultimate bond strength of reinforcements in steel fiber reinforced concrete.

\section{Notations}

$u_{c} \quad$ Ultimate bond strength

$f_{c}^{\prime} \quad 28$ days concrete compressive strength

$c_{\min }$ Minimum concrete cover

$d \quad$ Diameter of the embedded bar

$l_{d} \quad$ Embedded length of the bar

$f_{c m} \quad$ Mean compressive strength of concrete

$c_{f} \quad$ Steel fibers factor as 1 when $\frac{V_{f} l_{f}}{d_{f}} \leq 0.25$ and $c_{f}=1+0.34 \sqrt{\frac{V_{f} l_{f}}{d_{f}}}$ for $\frac{V_{f} l_{f}}{d_{f}}>0.25$

$c \quad$ Concrete cover

$l_{f} \quad$ Length of steel fibers

$d_{f} \quad$ Diameber of steel fibers

$f_{t} \quad$ Tensile strength of concrete

$K \quad$ Fibers content in $\mathrm{kg} / \mathrm{m}^{3}$

$E_{c} \quad$ Modulus of elasticity of concrete

$\rho_{s v} \quad$ Transverse reinforcement ratio

$k_{1} \quad 0.32$ for fiber reinforced high strength concrete

$k_{2} \quad 17.74$ for fiber reinforced highstrength concrete

[7] Romano, G. Q., Silva, F. A., Toledo Filho, R. D., Fairbairn, E. M. R., Battista, R. C. "Mechanical characterization of steel fiber reinforced self-compacting refractory concrete", In: Proceedings of the 5th International RILEM Symposium on Self-Compacting Concrete, Gent, Belgium, 2007, pp. 881-886.

[8] Akcay, B., Tasdemir, M. A. "Mechanical behaviour and fibre dispersion of hybrid steel fibre reinforced self-compacting concrete", Construction and Building Materials, 28(1), pp. 287-293, 2012. https://doi.org/10.1016/j.conbuildmat.2011.08.044

[9] Pająk, M., Ponikiewski, T. "Flexural behavior of self-compacting concrete reinforced with different types of steel fibers", Construction and Building Materials, 47, pp. 397-408, 2013. https://doi.org/10.1016/j.conbuildmat.2013.05.072

[10] Sezer, G. İ., Yazici, Ş., Sezer, A. "Dependence of Impact Resistance of Steel Fiber Reinforced Concrete on Aggregate Origin", Acta Physica Polonica A, 128(2-B), pp. 37-39, 2015. https://doi.org/10.12693/APhysPolA.128.B-37

[11] Ozyurt, N., Mason, T. O., Shah, S. P. "Correlation of fiber dispersion, rheology and mechanical performance of FRCs", Cement and Concrete Composites, 29(2), pp. 70-79, 2007. https://doi.org/10.1016/j.cemconcomp.2006.08.006 
[12] Ali, A., Iqbal, S., Holschemacher, K., Bier, T. A. "Effect of Fibers on Bond Performance of Lightweight Reinforced Concrete", Periodica Polytechnica Civil Engineering, 60(1), pp. 97-102, 2016. https://doi.org/10.3311/PPci.8080

[13] Nithya, B., Srinivasan, P., Suji, M., Lokesh kumar, P. "A Comparative Study on Bond Strength of Reinforcing Steel in Bottom Ash Concrete and Controlled Concrete", International Journal of Innovative Research in Science Engineering and Technology, 4(6), pp. 1770-1776, 2015.

[14] Zhao, Y., Lin, H., Wu, K., Jin, W. "Bond behaviour of normal/recycled concrete and corroded steel bars", Construction and Building Materials, 48, pp. 348-359, 2013.

https://doi.org/10.1016/j.conbuildmat.2013.06.091

[15] Sonebi, M., Cleland, D., Anuar, I. "Bond strength between reinforcement and self-compacting concrete", In: Proceedings of 4th Symposium on Bond in Concrete: Bond, Anchorage, Detailing, Brescia, Italy, 2012, pp. 267-272.

[16] Schumacher, P., Vliet, A. B., Braam, C. R., den Uijl, J. A., Walraven, J. C. "Bond OF Reinforcing Bars in Self-Compacting Steel Fiber Reinforced Concrete", In: Proceedings of the 3rd International Symposium, Bond in Concrete - From Research to Standards, Budapest, Hungary, 2002, pp. 823-830.

[17] Iqbal, S., Ali, A., Holschemacher, K., Bier, T. A. "Mechanical properties of steel fiber reinforced high strength lightweight self-compacting concrete (SHLSCC)", Construction and Building Materials, 98, pp. 325-333, 2015. https://doi.org/10.1016/j.conbuildmat.2015.08.112

[18] Betterman, L. R., Ouyang, C., Shah, S. P. "Fiber-matrix interaction in microfiber-reinforced mortar", Advanced Cement Based Materials, 2(2), pp. 53-61, 1995. https://doi.org/10.1016/1065-7355(95)90025-X

[19] European Federation of National Associations Representing for Concrete (EFNARC) "Specifications and Guidelines for SelfCompacting Concrete", EFNARC, Surrey, UK, 2002.

[20] Sahmaran, M., Yurtseven, A., Yaman, I. O. "Workability of hybrid fiber reinforced self-compacting concrete", Building and Environment, 40(12), pp. 1672-1677, 2005. https://doi.org/10.1016/j.buildenv.2004.12.014

[21] Dhonde, H. B., Mo, Y. L., Hsu, T. T. C., Vogel, J. "Fresh and Hardened Properties of Self-Consolidating Fiber-Reinforced Concrete", ACI Materials Journal, 104(5), pp. 491-500, 2007. https://doi.org/10.14359/18905

[22] Ding, Y., You, Z., Jalali, S. "Hybrid fiber influence on strength and toughness of RC beams", Composite Structures, 92(9), pp. 20832089, 2010.

https://doi.org/10.1016/j.compstruct.2009.10.016

[23] Ding, Y., You, Z., Jalali, S. "The composite effect of steel fibres and stirrups on the shear of beams using self-consolidating concrete", Engineering Structures, 33(1), pp. 107-117, 2011. https://doi.org/10.1016/j.engstruct.2010.09.023

[24] Atiş, C. D., Karahan, O. "Properties of steel fiber reinforced fly ash concrete", Construction and Building Materials, 23(1), pp. 392-399, 2009.

https://doi.org/10.1016/j.conbuildmat.2007.11.002
[25] Rambo, D. A. S., de Andrade Silva, F., Filho, R. D. T. "Effect of steel fiber hybridization on the fracture behavior of self-consolidating concretes", Cement and Concrete Composites, 54, pp. 100-109, 2014.

https://doi.org/10.1016/j.cemconcomp.2014.02.004

[26] Sahmaran, M., Yaman, I. O. "Hybrid fiber reinforced self-compacting concrete with a high-volume coarse fly ash", Construction and Building Materials, 21(1), pp. 150-156, 2007.

https://doi.org/10.1016/j.conbuildmat.2005.06.032

[27] Iqbal, S., Ali, A., Holschemacher, K., Bier, T. A. "Effect of change in micro steel fiber content on properties of High strength Steel fiber reinforced Lightweight Self-Compacting Concrete (HSLSCC)", Procedia Engineering, 122, pp. 88-94, 2015. https://doi.org/10.1016/j.proeng.2015.10.011

[28] Olivito, R. S., Zuccarello, F. A. "An experimental study on the tensile strength of steel fiber reinforced concrete", Composites Part B: Engineering, 41(3), pp. 246-255, 2010. https://doi.org/10.1016/j.compositesb.2009.12.003

[29] Siddique, R., Kaur, G., Kunal "Strength and permeation properties of self-compacting concrete containing fly ash and hooked steel fibres", Construction and Building Materials, 103, pp. 15-22, 2016. https://doi.org/10.1016/j.conbuildmat.2015.11.044

[30] Abbass, W., Khan, M. I., Mourad, S. "Evaluation of mechanical properties of steel fiber reinforced concrete with different strengths of concrete", Construction and Building Materials, 168, pp. 556569,2018 .

https://doi.org/10.1016/j.conbuildmat.2018.02.164

[31] Iqbal, S., Ullah, N., Ali, A. "Effect of Maximum Aggregate Size on the Bond Strength of Reinforcements in Concrete", Engineering, Technology \& Applied Science Research, 8(3), pp. 2892-2896, 2018. [online] Available at: https://www.etasr.com/index.php/ ETASR/article/view/1989

[32] Garcia-Taengua, E., Martí-Vargas, J. R., Serna, P. "Bond of reinforcing bars to steel fiber reinforced concrete", Construction and Building Materials, 105, pp. 275-284, 2016. https://doi.org/10.1016/j.conbuildmat.2015.12.044

[33] Orangun, C. O., Jirsa, J. O., Breen, J. E. "A Reevaulation of Test Data on Development Length and Splices", ACI Journal Proceedings, 74(3), pp. 114-122, 1977. https://doi.org/10.14359/10993

[34] International Concrete Federation (fib) "Model Code 2010- Final draft, Volume 1", fib, Lausanne, Switzerland, 2012.

[35] Harajli, M. H. "Comparison of Bond Strength of Steel Bars in Normal- and High-Strength Concrete", Journal of Materials in Civil Engineering, 16(4), pp. 365-374, 2004. https://doi.org/10.1061/(ASCE)0899-1561(2004)16:4(365)

[36] Yazici, Ş., Arel, H. Ş. "The effect of steel fiber on the bond between concrete and deformed steel bar in SFRCs", Construction and Building Materials, 40, pp. 299-305, 2013. https://doi.org/10.1016/j.conbuildmat.2012.09.098

[37] Li, X., Zhang, J., Liu, J., Cao, W. "Bond Behavior of Spiral Ribbed Ultra-high Strength Steel Rebar Embedded in Plain and Steel Fiber Reinforced High-Strength Concrete", KSCE Journal of Civil Engineering, 23(10), pp. 4417-4430, 2019. https://doi.org/10.1007/s12205-019-2449-0 